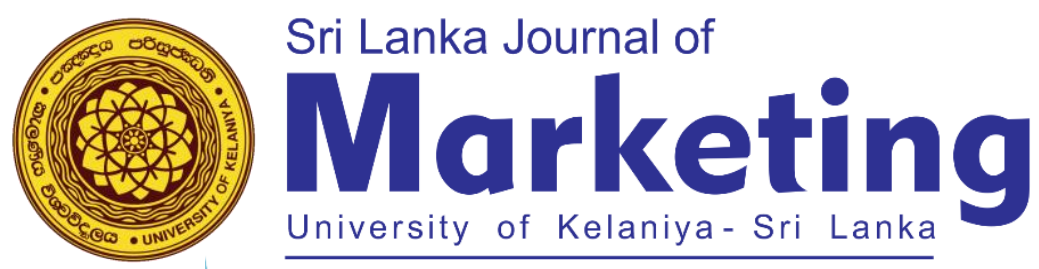

\title{
Employee's Job Satisfaction with Computer Mediated Communication System
}

\begin{tabular}{|c|}
\hline Gunawardana, T. S. L.W. \\
Senior Lecturer, University of Ruhuna, Sri Lanka \\
gunawardana@badm.ruh.ac.lk \\
Sirimanna, U. I. \\
Engineer, Ceylon Electricity Board, Sri Lanka \\
imaya1976@gmail.com
\end{tabular}

\section{ABSTRACT}

To fill the gaps in the computer mediated communication literature and provide useful information on interpersonal relationships within an organization, this study aims to investigate how computer mediated communication (CMC) system have impacted on employee's job satisfaction of Ceylon Electricity Board, Sri Lanka. An empirical research was conducted to test the hypothesized relationships based on a conceptual framework developed through a comprehensive literature review on CMC and job satisfaction. Through a literature support this model consisted of three independent variables (i.e., electronic mails, instant messaging and computerized maintenance management) in computer mediated communication system and a dependent variable which is job satisfaction. The sample of the study consisted of 100 respondents representing executive and medium level technical service (MLTS) staff of the transmission division of Ceylon Electricity Board in Sri Lanka. Self-administered questionnaire and the web-based questionnaire was used to collect primary data. The data were analyzed with Partial Least Squares path modeling (PLS) to test the hypotheses of the study. The research findings indicated that computerized maintenance management is the most significant factor impacting on the employees' job satisfaction. Moreover, it also identified that there is a positive and statistically significant impact of instant messaging and electronic mails on employees' job satisfaction. The results provide valuable input regarding the instant messaging and job satisfaction. Therefore, managers should have to pay their more and more attention in order to improve instant messaging as one of the communication media in an organization. In this research considered only three CMC dimensions which influence the job satisfaction. But there are more CMC dimensions used as organizational communication in future studies.

Keywords: Computer Mediated Communication System, Computerized Maintenance Management Solution Electronic Mails, Instant Messaging, Job Satisfaction 


\section{INTRODUCTION}

\subsection{Background of the Study}

With the enormous competition in business world, the most of the organizations eager to adopt new technological improvements and innovations to their practices for maximizing the employees and organizational performance (Paraskeva, Eriksson, Johansson, \& Peter, 2019; Bordi, Tammi, \& Okkonen, 2014). The high speed communication is most important fact in current competitive business world. The computer-mediated communication system (CMC) has done significant changes in the ways people communicate and associate with each other in both government and private sector organizations today (Jayalal \& Balasuriya, 2015). With the use of CMC system information can be sent to single as well as multiple recipients thus making the distribution of information easier and quicker than ever before (Wellman, Salaff, Dimitrova, \& Garton, 1996). With this rapid change in communication technology, the organizational culture and employees' working environment, organizational language, interpersonal relationships of the employee have totally changed as a result of CMC effects. These changes which were created due to CMC system influence has make significant impact on employees work life and their job satisfaction (Dhir, 2018). Therefore, most of the organizations are adopting CMC system as their organizational communication today. Therefore, it will have added value to study the impact of CMC on Job satisfaction of employees presently.

Nevertheless, the employees should have up-to-date technological skills or have to develop those skills to adapt the digitalizing work environment. Learning and adapting to new technologies may increase the workload and cause stress (Bordi, Heikkilä \& Okkonen, 2014). The number of technologies used at work, constant changes in ICTs, plus malfunctions and usability problems of the systems may increase the risk of lowered well-being and satisfaction (Day, Scott \& Kelloway, 2010). Thus, if CMC system has an impact on job satisfaction, then organizations using CMC system have an effective tool for influencing employee job satisfaction. With the technological advancements, most of the organizations get improved by adopting latest components to their communication practices (Lee, 2011).

This study intends to find out impact of computer mediated communication system on the job satisfaction of CEB in Sri Lanka. Literature on CMC system suggests that significant number of studies has not been conducted in services sector of Asian region to find out the relationship among these variables. Most of the researches (Belle, Hall, Riekert, \& Muganda, 2007, Lau, 2014, Bob \& Sooknanan, 2014) have conducted researches on the topic of impact of computer mediated communication on interpersonal relationship of couples, groups or workers. Nevertheless, each and every organization not only in western countries all over the world are using CMC system as their main communication media, there is only few studies done on worker's performance or employee satisfaction in CMC environment. However, most of the CMC studies focus on the CMC effect, use 
and user satisfaction. The Sri Lankan researcher (Samaravicrama, 2017) has investigated the related factors that effect on research productivity in the Computer Mediated communication environment of Sri Lankan academics in his research. In Jayalal \& Balasuriya's (2015) research their target was to find the impact of Social Network Usage on the Job Performance of IT Professionals in Sri Lanka.

According to the literature found (Epure, Ionescu, \& Nancu, 2013), (Giri, \& Kumar, 2010), (Mukahi, Nakamura, \& Not, 2003) there are very few number of research were done in the world to examine the impact of CMC on job satisfaction. According to Giri \& Kumar, (2010) identifies organizational communication had a significant effect on job satisfaction and job performance of the employees. The analysis further indicated that the employees at different levels perceived job satisfaction differently. Thus, it can be seen job satisfaction and performance are very much dependent on the communication behavior of the organization. A research done by Epure, Ionescu, \& Nancu, (2013) evaluate the communication influences on job satisfaction among Romanian employees and they found that communication has a significant influence on employees' behavior at work and their sentiment of satisfaction. A research on the topic of the empirical study on impacts of computer-mediated communication management on Job Satisfaction (Mukahi, Nakamura \& Not, 2003), concludes that those organizations that manage $\mathrm{CMC}$ well can increase productivity, increase employee job satisfaction, better retain their most valued personnel, and better survive in today's knowledge society. If consider the local context Rathnathilaka, Madushani, \& Perera,'s (2016) have done a research on social network usage of government employees in Sri Lanka their discovery was that government employee's age is the only factor that affects for using CMC and social media sites. As well as Samarawickrama, (2017) has done a research to find factors that motivate to use computer mediated communication (cmc) on faculty research productivity in Sri Lankan. Several factors such as individual, institutional, technological factors, Task related factors were found to be associated with research productivity that leads to the use of CMC. Therefore, in Sri Lankan context, a research to find the direct impact of CMC system on and job satisfaction in service sector of Sri Lanka is still not done. So, there is a problem weather $\mathrm{CMC}$ practices can improve the job satisfaction of employees. Therefore, this research study is most important to fill up that research gap identified in Sri Lankan context. As well as CMC systems become the part of the organizational culture in CEB in very fast. When the organization try to attain its goals effective and efficient manner the human resource is more vital among other resources in the organization. Therefore, it is essential to examine how the CMC impact on job satisfaction in $\mathrm{CMC}$ environment and it is most important for the future development of the organization.

Though, most of the CMC system impact studies done for examine the direct impact of CMC system in interpersonal relationship, user satisfaction, working environment, but they have not measured CMC system impacts applying to job satisfactions of the employees. On the other hand, CEB straightaway 
implementing several web based information systems using CMC such as computerized Maintenance Management System (CMMS), Human Recourse Management Information System (HRMIS), Enterprise Resource Planning System (ERPS), and Inventory Management System and in addition to the usual email and Instant massages for all administrative purposes. Because of introducing of such management information systems, the paper work has been stopped in the organization. Today CEB employees ought to do major parts of their administrative work with use of CMC system. If the employee interested or not, they have to be a part of the CMC system in the organization. Therefore, it is decided to do this research to identify the level of satisfaction of employees in CEB with new CMC environment. The research question, therefore, leading direction to an empirical investigation in this study is "Does the adaptation of computer mediated communication (CMC) system lead job satisfaction of the employees in Ceylon Electricity Board, Sri Lanka?"

\section{LITERATURE REVIEW}

\subsection{Traditional Communication to Modern Communication}

Bordi, Tammi,, \& Okkonen (2014) reveals that computer mediated communication and electronic documents are mostly favored over traditional telephone calls and paper, as they seem to be easier to manage and increase the opportunity of having further control over employee's work. Before $70^{\text {th }}$ decade some people thought using computers for information exchange as dangerous. Some people feel threatened by computers (Dahanayake, 2015). But after1970s, some people start to feel computers enhance their opportunities of making any information available to someone and supporting information exchange easily and speedily irrespective of geographical distances (Palme, 2000).

With the development of computer and internet technology, computer mediated communication (CMC) appropriated all forms of communication facilities in the workplace. CMC improved vertical and horizontal information flow more efficiently across organizations as well as information intake to the organization. Not only the fastness of CMC practice but also volume and portion in the organizational work done are getting greater and greater rapidly. As a result of factors such as greater access to organizational power, decision-making and creative processes it has also been credited with significant improvement in task efficiency, planning, promoting timely and complete feedback, controlling organizational activities, managing time, initiating action plans, responding to the environment, planning flexible work schedule (Bob \& Sooknanan, 2014).

\subsection{Computer Mediated Communication (CMC)}

Different authors have different approaches towards defining computer mediated communication. According to the Kim (2002), computer mediated communication is defined as any interpersonal or group level communication which is mediated by a computer, but mass communication is eliminating 
here. December (1997) defined that "a process of human communication via computers, involving people, situated in particular contexts, engaging in processes to shape media for a variety of purposes" (p.3), while based on the definition of Stasser (1992) CMC can be defined as a process of negotiating the meaning of various situations arises between the group of social actors. As claims of Metz (1992) computer-mediated communication (CMC) is described as any communication patterns mediated through the computer.

There are lots of advantages that employees can enjoy because of CMC systems introduced and developed in an organization. As claims of Rowley(1999), CMC makes responds more quickly than was possible through a letter or memo as well as can attached more files and communicate with groups on one occasion. So, CMC creates faster, speeder and reliable communication service. Further he discussed the management and development of organizations considered to be centralized with CMC, and, indeed, the style of communication can influence interpersonal relationships, and in turn, factors such as commitment and motivation. Gush (1999) conducted a research to examine the potential and limitations of computer mediated communication (CMC) in an educational context at Bournemouth University on two courses to serve the needs of students out on their work placement year. There he found that the $\mathrm{CMC}$ is its ability to facilitate learning at a distance by providing a sophisticated tool for communication. The advantage of this is, therefore it creates new knowledge and understanding while working collaboratively with a view and can deliver against desired outcomes (Bordi, Tammi,, \& Okkonen, 2014).

\subsection{Dimensions of CMC}

Since computer mediated communication is rapid developing technology its dimensions are vary with time. The various researches describe CMC system with various models. According to Harold Dwight Lasswell's ' $5 \mathrm{~W}$ ' theory, CMC system is a new form of communication with its own five characteristics Subject, Host, Information resource, Channel, Relations and Effects. Further, researcher Yu (2011) identifies CMC system composed of human and computers, absorbs and then extends the advantages of all former formats of communication, acceptance the instant interaction of oral communication, the intellectual logics of printing dissemination, and the vivid images of movie and television.

The researcher Simpson, (2002) further describes that where interaction takes place in real time synchronous CMC and where participants are not necessarily online simultaneously asynchronous CMC. Synchronous CMC includes various types of text-based online chat, computer, audio, and video conferencing; asynchronous CMC encompasses email, discussion forums, and mailing lists. Stefan (2008) has done a research to explore formal and informal dimensions of CMC. In his paper he has further developed Fish's (1990) model of distinguishes characteristics of informal and formal dimensions of computer mediated communication (CMC). His findings revealed that a medium ( 
Channel) may be more or less useful for supporting informal or formal communication. In addition to that, Stefan (2008) has done a research to explore formal and informal dimensions of CMC.

The Sri Lankan researches, Dahanayake (2015), Jayalal \& Balasuriya (2015), Rathnathilaka, Madushani, \& Perera (2016), Samarawickrama (2017), Jayaweera, Sanmugam, \& Wanasundara (2006) highlights that still CMC has not spread over the country equally in all areas. Even though there is no more number of previous researches linking this title which is in Sri Lankan context, some contents can be mentioned as follows. According to Samarawickrama (2017), the usage of computer related communication has grown in government institutes of Sri Lanka began in 1960. With the establishment of Sri Lanka Telecom (SLT) in 1991 and the initiation of SLT Internet service facility in 1996 adaptation to $\mathrm{CMC}$ is increased in public and private sector organizations. Therefore, CMC systems and its dimensions such as instant messaging, email, chat rooms, online forums, and social network services start to play major role in organizational communication in education, health, banking, travel \&Tourism and manufacturing industries in Sri Lanka. The commonly used CMC dimensions in Ceylon Electricity Board are discussed follows according to different views of different authors to setup the hypothesis.

\subsubsection{E-mails}

Electronic mail or e-mail is defined as the transmission of messages over communications networks. Those massages containing text, documents, sound, pictures, and even computer programs. Computers are generally used as terminals, but electronic agendas, cell phones, data communication terminals or other data exchange equipment can also be used to send emails (Beal, 2019). Currently more than 600 million people around the world use email as a means of communication for personal and business communication needs (Mertena \& Gloorb, 2009). With the development of the World Wide Web, email also continued to developed, with providers such as Hotmail, Yahoo, and Google offered free email accounts.

E-mail possess the highest level of social presence, followed by other CMC dimensions as claims of $(\mathrm{Tu}, 2002)$. He reveals also email is more public in public and private sector organizations today. Quaresma , da Silva , \& Marreiros , (2013) empirically studied the use of e-mail in an organizational context, using a sample of the Portuguese population with an active e-mail account assigned by the employer. The results show that most users have what is considered appropriate behavior. The paper of Smith \& Tabak, (2009) provides evidence of work outcomes of e-mail monitoring regarding employee attitudes and behaviors such as organizational commitment, job satisfaction, and performance.

Not only the positive impact, there are some drawbacks as well. Mertena \& Gloorb,(2009) calculated e-mail responsiveness and conducted an individual job satisfaction survey. They identified patterns of productive and less-productive e-mail usage. Results indicate that central network position reduces e- 
mail responsiveness, while this position in the organization's social network also seems to be correlated with lower job satisfaction. The team which sent and received the most e-mail reported the lowest job satisfaction.

\subsubsection{Instant Messaging}

Instant messaging (IM), is the near real-time conversation in a private, back and forth style of communication of two users by exchanging messages through a stand-alone application or embedded software (Rouse, 2008). With the development of technology now it can be transfer not only text messages but also transfer files and images by using IM. In order to Larson (2011)'s definition Instant messaging (IM) technology is a type of online chat that offers real-time text transmission over the Internet. More advanced instant messaging can add file transfer, clickable hyperlinks, Voice over IP, or video chat. Instant messaging is gaining popularity in organizations because it speeds up the communication process.

Cho, Trier, \& Kim (2005) states that IM as a double-edged sword. Because when IM help to facilitate quality communication and trust, on the other hand it interrupts the work. However, when the negative effects if IM are negligible. However, he further states that IM can usefully increase other CMC tools and create an effective and comprehensive CMC environment in the workplace therefore it leads to better work performance of employees. Another research has done by Sias, Pedersen, Gallagher, \& Kopaneva (2012) to examine teleworkers' job satisfaction related to the use of and satisfaction with a variety of communication channels and he reveals that Teleconferencing and instant messaging ranked as least satisfying among a range of communication channels available to teleworkers.

\subsubsection{Computerized Maintenance Management Systems (CMMS)}

A computerized maintenance management system (CMMS) is a software package designed to maintain a computer database for an organization's maintenance operations and human resources function (DeSanctis \& Poole, 1994). Computerize Maintenance Management system (CMMS) is help for scheduling all types of maintenance jobs such as maintenance operations, labor handling, purchasing and inventory handling and providing statistical reports. Each responsible employee for above activities can involve for their job simultaneously if they are geographically dispersed because of CMC. CMMS is leading CMC system in Sri Lanka for utility management. A computerized Maintenance Management System (CMMS) is a computer software program designed to assist in the planning, management and administrative functions required for effective maintenance. According to the findings of Higgins, Brautigam, \& Mobley, (1995) that CMMS manage maintenance information contributes to improved communication and decision-making capabilities and improve the information and communication facilities of repair needs and work priorities. Further they found in their research that CMMS has the 
capability of improving coordination through closer working relationships between maintenance and production. So it increased maintenance responsiveness of employees.

Rastegari \& Mobin (2016) says that electronic communication between offices in an organization improve with CMMS because they can send work assignments to maintenance workforce through mobile devices and so they can operate more efficiently in the field, for timely completion of required maintenance and repairs. On top of that, CMMS lets your team communicate in a more efficient manner which means the work can be started faster and subsequently finished under set deadlines. To attain a better understanding of how advanced CMMS trigger satisfaction amid their resource (employees) hereby refer to Adaptive Structuration Theory (AST) to describe the process by which people incorporate advanced technologies into their work practices. Once applied, technologies should trigger structural change in terms of productivity, efficiency, and satisfaction to individuals and organizations (DeSanctis \& Poole, 1994).

\subsection{Employees' Job Satisfaction}

Various researchers and practitioners have provided their own definitions of what job satisfaction is. However, some of the most common definitions describe job satisfaction as a psychological, behavioural and occupational response by employees' towards fulfilment at their job. It is an expression of an employee pertaining to a particular segment of the work (For instance, reward, authority, peers). Kumar (2002) has defined the job satisfaction is a significant principle for the success of an organization where it is closely associated with life satisfaction. That means employees satisfaction is directly proportional to organizational performance. Therefore, employees can make or break an organization (Deal, 2007). Brief \& Weiss (2002) defined job satisfaction as "a pleasurable or positive emotional state resulting from the perception by the individual of his/her job as implementing or giving the opportunity to realize significant values available in the work, provided that these values are consistent with his/her needse (p.282). According to this definition that job satisfaction is somewhat subjective person to person. Weiss (2002) also defines same concept of" job satisfaction represents a person's evaluation of his or her job and work context (pp. 173). Satisfaction depends on the level of discrepancy between people expect to receive and what they experience. Further Locke (1976) defines job satisfaction as really a collection of attitudes about specific facets of the job. Employee satisfaction equivalent to the expectations of the employee about the workplace and his attitudes towards his job. So, the job satisfaction is also a moral obligation in many societies. Gradually it can conclude that job satisfaction is subjective, 'a happy worker is productive worker.'

The importance of job satisfaction for any organization is huge as it is linked to many variables, including productivity, absenteeism, turnover, etc. It is significant because a person's attitude and beliefs may affect his or her behavior (Saleem, Majeed, Aziz, \& Usman, 2013). If the employees in an 
organization satisfied with their job it will lower turnover, higher productivity, increased customer satisfaction, employee absenteeism, helps to earn higher revenues, satisfied employees tend to handle pressure (Okwudili, 2012). Therefore, if the company has satisfied employee base, that is the strength of the company. Perceived job satisfaction was measured by Epure, Ionescu, \& Nancu, (2013) using six dimensions, respectively named as working conditions, promotion opportunities, frequency of trainings, wage and compensations schemes, employee fluctuation and importance of work within organization in their research study. As well as according to Multi-Motivation Theory (Murasugi and Miki 1990), which was developed in Japan based on Maslow's (1954) and Herzberg's (1968) work motivation theories, that employees are motivated by four factors. They are working conditions, interpersonal relations, satisfaction with job content, and company policy.

Communication, as well, was a subject of interest to many researchers who discussed its impact on employee's job satisfaction. The results of (Jacobs, Yuo \& Chavez, 2016) research reveal that internal communication has a significant positive effect on employee satisfaction. Based on Attar \& Sweis (2010) communication are the variables that most contributed to employee satisfaction within contracting firms. Effective communication in combination with satisfied employees. The satisfied employee is mandatory for improving the firm performance in the coordination of resources. According to Epure, Ionescu, \& Nancu (2013) who did the research in Romanian company's job satisfaction is strongly affected by communication: the more individuals communicate within companies, the more satisfied they feel with their job. Number of researches have empirically founded that there was positive relationship between effective communication and job satisfaction. According to Giri \& Kumar, (2010) identifies organizational communication had a significant effect on job satisfaction and job performance of the employees. The analysis further indicated that the employees at different levels perceived job satisfaction differently. Thus, it can be seen job satisfaction and performance are very much dependent on the communication behavior of the organization.

\section{STUDY DESIGN AND METHODS}

\subsection{Conceptual Framework and Hypotheses}

As points outs by (Balouch \& Hassan, 2014) modern management science's philosophy considers job satisfaction as a baseline standard of satisfaction reported by many different characteristics of work and the workplace. There are various features of the work and the workplace that valued to job satisfaction. Researchers have attempted to explain the effects of CMC using different theories. From media richness theory Daft \& Lengel, (1986) suggests that e-mail is a leaner medium due to the text based and asynchronous nature of e-mail. The impact of communication channel satisfaction, personality, and job satisfaction could be explored from a social influence perspective (Fulk, Schmitz and Steinfield, 1990), or a media richness perspective to better predict how each variable will influence job satisfaction of 
teleworking employees (Waldeck, Seibold and Flanagin, 2004). The other study by Cameron \& Webster (2005) used the media richness theory to investigate why employees use IM at work. To attain a better understanding of how advanced CMMS trigger satisfaction amid their resource (employees) hereby refer to Adaptive Structuration Theory (AST) to describe the process by which people incorporate advanced technologies into their work practices (Gopal, Bostrom and Chin, 1993). Once applied, technologies should trigger structural change in terms of productivity, efficiency, and satisfaction to individuals and organizations (DeSanctis and Poole, 1994). Therefore, the present study developed the conceptual framework (figure 1) to investigate the impact of email, instant messaging and CMMS in the workplace and its correlation with two core concepts of media choice theories: media richness, social influence, and adaptive structuration theory (AST).

Figure 1: Conceptual Framework

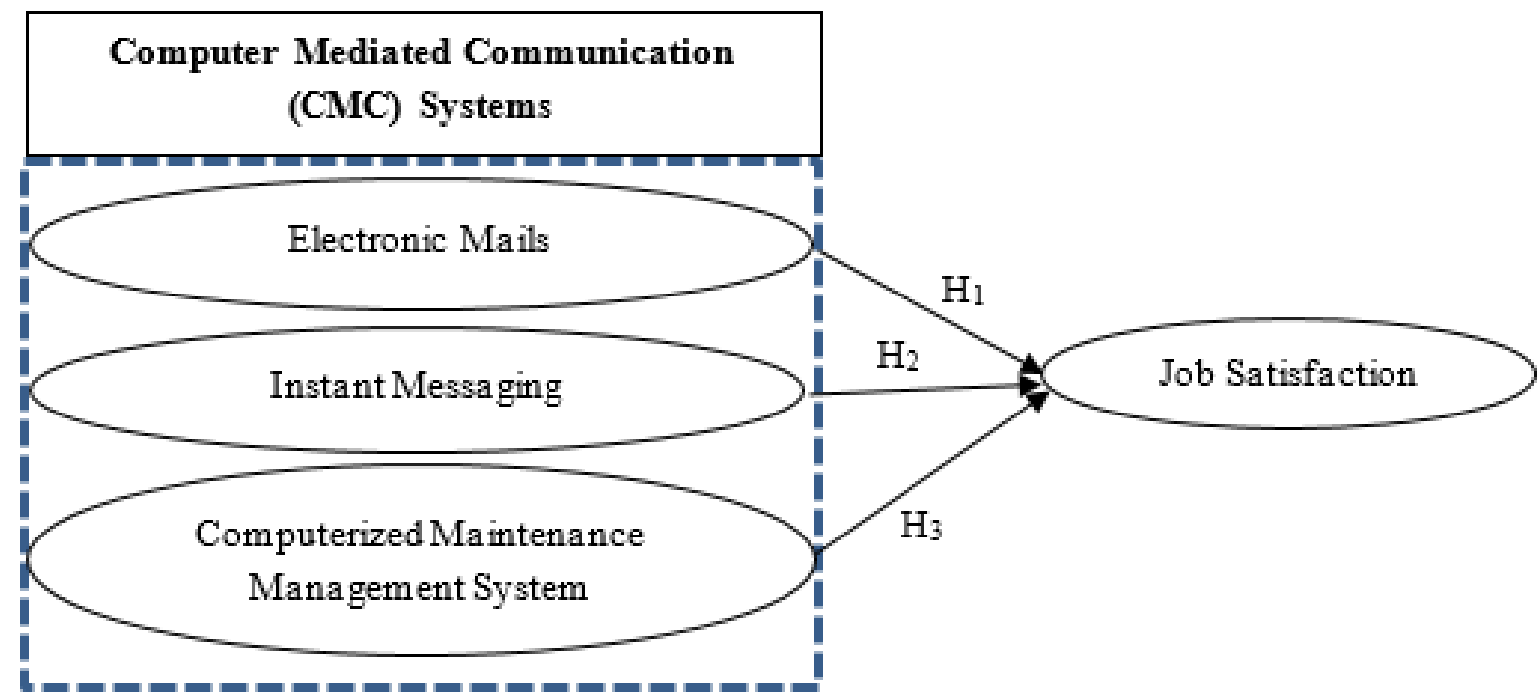

\subsubsection{Electronic Mails and Job satisfaction}

Bob \& Sooknanan (2014) and Urquhart, Bommelje, \& Schmid (2002) found that there is a positive relationship between $\mathrm{CMC}$ dimension of email with the job satisfaction. Based on the findings of Bob \& Sooknanan, (2014), it is evident that the majority of employees felt that email usage had increased productivity and efficiency in the workplace. Mukahi, Nakamura \& Not (2003) states that email usage is highly important for employees individually as well as for the performance of organisation. Further they say that those organizations managing CMC well can gain CMC effects, increase employee job satisfaction. The findings of all these research shows that electronic mail usage strongly effect on employee's job satisfaction. Based on the aforementioned arguments, the following hypothesis is formulated,

$H_{1}$ : There is a positive impact of electronic mails on job satisfaction. 


\subsubsection{Instant Messaging and Job Satisfaction}

As claims of Iskandar, Arham \& Shohaime (2017) there is significant relationship between the uses of instant messaging with performance. Instant messaging is one of the more prominent computer mediated communications which is able to boost an instant reaction, similar to face to face communication Ou, Sia \& Hui (2013) and Cameron \& Webster (2005) described instant messaging allows employees to communicate in real time and shows those who are online and currently available to receive messages. Lee (2011) found in her research which has been conducted to understand the potential impact of using IM in the workplace, the position power of the IM jointly influences employee satisfaction and subjective task complexity. Based on the above discussion following hypothesis is proposed.

$H_{2:}$ There is a positive impact of instant messaging on job satisfaction.

\subsubsection{Computerized Maintenance Management System (CMMS) and Job Satisfaction}

According to the findings of Higgins, Brautigam \& Mobley (1995) that CMMS manage maintenance information contributes to improved communication and decision-making capabilities and improve the information and communication facilities of repair needs and work priorities. Further he found in his research that CMMS has the capability of improving coordination through closer working relationships between maintenance and production. So it increased maintenance responsiveness of employees. Rastegari \& Mobin (2016) says that electronic communication between offices in an organization improve with CMMS because they can send work assignments to maintenance workforce through mobile devices and so they can operate more efficiently in the field, for timely completion of required maintenance and repairs. Even though prior empirical evidence on these relationships are less based upon the preceding discussion following hypothesis is proposed.

\section{$H_{3}$ : There is a positive impact of CMMS on job satisfaction.}

\subsection{The Sample, Study Variables, Questionnaire Design and Data Collection}

Since Ceylon Electricity Board is a multi-divisional organization spread over to every nook of the country, it is well recommended to do a descriptive cross sectional research study to test the formulated hypothesis. The primary data was collected using a structured questionnaire and the secondary data was collected from previous research papers, Internet and books. The researcher survey carried out with mixed mode and it also included quantitative and qualitative questionnaires. Face to face interview would be helped to identify existing issues and base on that researched has been created the questionnaire. Ceylon Electricity Board is a large scale company which is holding more than 16,000 numbers of employees. Although the CEB employees are the population of the study, it is not fair to 
measure all the employees for this study because only about 3000 employees are executive grade and MLTS grade employees out of the total number of employees and all other employees are operational level. Key respondent technique has been used by researchers when the survey instrument applied for the study is a specialized one (Consuegra, 2008). Additionally, the research is involved only on the manipulators in transmission division who are directly involved into CMC system for their day today office work. Therefore, the study selected executive and medium level technical service (MLTS) staff of the transmission division of CEB as the population of the study, while executive and medium level technical staff grade employees of Western and Southern provinces are the sample in this research. Simple random sampling method was applied to select the managerial level employee in transmission division of CEB as a unit of this analysis. To select sample from population, a list of Executive and MLTS grade employees was prepared based on the sampling frame. After that, an identification number to each element on the lists was assigned.

Out of 200 questionnaires delivered, 50 were delivered as a web based questionnaire and response rate was $50 \%$ and the remaining 150 questionnaires were distributed personally. However, 75 questionnaires were usable to the survey after the personal distribution as there were six incomplete questionnaires, while response rate was 54\%. As such, the total of 100 usable questionnaires were considered for the analysis with 53\% overall response rate. Demographic data analysis has done through the SSPS and 58 respondents were male and 42 respondents were female. The experience of the respondents to use CMC as follows, $80 \%$ of respondents have used CMC more than 05 years, $8 \%$ of respondents use 3-5 years, $9 \%$ of respondents use 1-3 years and 3\% of respondents use less than one year. According to the respondents, 51 have selected mobile phone is the most important and useful communication method, 10 have selected fixed (land) telephone, 25 respondents selected e-mails, 11 respondents selected face to face, and 3 respondents have selected instant messaging as the most important and useful communication method. A structured questionnaire used in the study consisted of three parts including the first part for the demographic data of the respondents, the second part to elaborate the background information of the respondents, and the third part relates to hypothesis of the study. The four study constructs of the study i.e., electronic mails, instant messaging (IM), computerized maintenance management system (CMMS) and job satisfaction were operationalized as multi-item constructs. The seven items of the electronic mails were adopted from Bälter (1998); Iskandar, Arham \& Shohaime, (2017); and Quaresma, Da Silva \& Marreiros (2013). Instant messaging consisted of seven items were adopted from Mahatanankoon (2010); Mukahi, Nakamura, \& Not (2003); Lee, (2011); and Iskandar, Arham \& Shohaime (2017), while computerized maintenance management system (CMMS) consisted of seven items adopted from Mukahi, Nakamura \& Not, (2003); and Chauhan \& Singh (2016). Job satisfaction consisted of 11 items adopted from Mukahi, Nakamura \& Not (2003). 


\section{DATA ANALYSIS AND RESULTS}

Structural equation modeling (SEM) was used in this study to assess the predictive power of theoretical model and testing the formulated hypothesis. Internal consistencies of the constructs were examined using the composite reliability index. Discriminant validity indicates the extent to which a given construct is different from other latent constructs. Fornel and Larcker (1981) has suggested to use the average variance extracted (AVE) in evaluating discriminant validity of constructs. Partial least square technique using Smart PLS version 20 was used to test the hypotheses, while SPSS software package was used to check frequency statistics of demographic variable.

Table 1: Discriminant Validity of the Latent Variables

\begin{tabular}{lcccc}
\hline & $\mathbf{1}$ & $\mathbf{2}$ & $\mathbf{3}$ & $\mathbf{4}$ \\
\hline Electronic mails & $\mathbf{0 . 8 6 5}$ & & & \\
\hline Instant Messaging & 0.209 & $\mathbf{0 . 8 7 3}$ & & \\
\hline CMMS & 0.438 & 0.007 & $\mathbf{0 . 9 1 3}$ & $\mathbf{0 . 9 1 2}$ \\
\hline Job satisfaction & 0.587 & 0.232 & 0.619 &
\end{tabular}

Source: Survey Data (2021)

Discriminate validity is the degree to which any single construct is different from the other constructs in the model (Carmines \& Zeller, 1979). Discriminant validity is assessed by the test provide by Fornell and Larcker (1981) in which the pair-wise latent variable correlations between factors obtained are compared with the square root of the average variance extracted estimates for the constructs making up each possible pair as illustrates in table 1.

\subsection{PLS Path Model Estimation}

In Partial Least Squares (PLS) method, structural model and hypothesis were tested by computing path coefficients $(\beta)$. Because PLS does not require a normally distributed data it is evaluated with R-squared calculation for dependent latent variables (Cohen, 1988) and the average Variance extracted (Fornell \& Larchner, 1981). As shown in the Table 2, results obtained by analysing the collected data and all the variables are yielded significant values.

Table 2: Results of PLS Path Model Estimation

\begin{tabular}{|l|c|}
\hline & Job Satisfaction $^{\mathrm{a}}$ \\
\cline { 2 - 2 } Path & Estimates (t-Value) \\
Electronic mails & $0.35\left(4.68^{* * *}\right)$ \\
Instant Messages & $0.16\left(2.07^{* *}\right)$ \\
Computerized Maintenance Management Systems (CMMS) & $0.46\left(6.91^{* * *)}\right.$ \\
Coefficient of Determination ( $\left.{ }^{2}\right)$ & 0.35 \\
Electronic mails & 0.15 \\
Instant Messages & 0.46 \\
Computerized Maintenance Management Systems (CMMS) & \\
$\mathrm{F}^{2}$ Coefficient & 0.20 \\
Electronic mails & \\
\hline
\end{tabular}




\begin{tabular}{|l|c|}
\hline Instant Messages & 0.05 \\
Computerized Maintenance Management Systems (CMMS) & 0.37 \\
$\mathrm{Q}^{2}$ & 0.234 \\
\hline
\end{tabular}

$* * * p<0.001 ; * * p<0.01 ; * p<0.05$

${ }^{a}$ Dependent variable

Source: Survey Data (2021)

According to the results indicates in table 2 , it reveals that electronic mails has a positive and statistically significant relationship with employees' job satisfaction $(\beta=0.35, t=4.68, p<0.001)$ and there is a positive relationship between instant messaging and employees' job satisfaction $(\beta=0.16, t=2.07, p<$ $0.01)$. The results indicate that the relationship is in the expected direction and the relationship is statistically significant. The relationship between CMMS and employees' job satisfaction $(\beta=0.46, t=$ $6.91, p<0.001)$ is also positive and statistically significant. The structural model in figure 2 is evaluated with respect to the estimates and hypothesis tests regarding the causal relations between exogenous and endogenous variables specified in the path diagram. Standard errors and test statistics for the relevant parameters are estimated in SmartPLS with the Bootstrapping option.

Figure 2: Structural Model Showing Path Coefficients

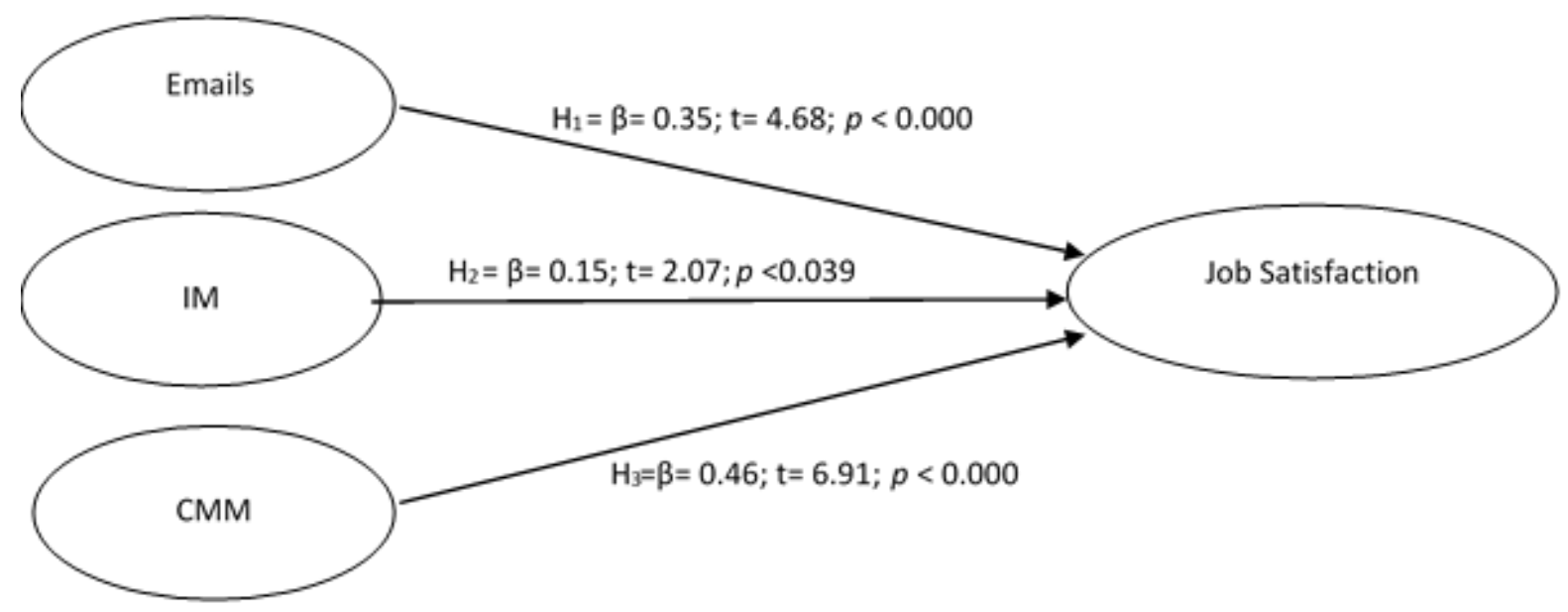

A confirmatory factor analysis is carrying out on the data to verify reliability of each measurement scale of variables (Forza, 2002). Standardized factor loadings and outer loading factors of each item and the composite reliability and AVE value of each construct is presented in table 3 . According to the provided guide lines of Bagozzi, Yi, \& Phillips, (1991) the composite reliability of various dimensions is higher than 0.7 and Average Variance Extracted (AVE) is higher than 0.5 is accepted as significant levels. According to Hair, Black, Babin, \& Anderson, (2007) generally larger loadings are the stronger and more reliable the measurement model. The factor loadings of the latent variables are high and statistically significant. According to the results of CFA, this confirms that the indicator variables and their respective underlying constructs are acceptable. The composite reliability values of the study constructs also reveal that the measurement model is reliable 
Table 3: Confirmatory Factor Analysis of Constructs

\begin{tabular}{|c|c|c|}
\hline Item & $\begin{array}{l}\text { Standardized } \\
\text { Factor } \\
\text { Loadings } \\
\text { (t- Value) }\end{array}$ & $\begin{array}{l}\text { Composite } \\
\text { Reliability } \\
\text { /AVE }\end{array}$ \\
\hline Electronic Mails & & $0.865 / 0682$ \\
\hline The replies to my email messages are immediate and within satisfied speed & $0.822(22.56)$ & \\
\hline It is easy to express what I want to communicate through emails & $0.786(14.57)$ & \\
\hline $\begin{array}{l}\text { Since email communication is mostly used in my work place it is easy to } \\
\text { work }\end{array}$ & $0.866(33.02)$ & \\
\hline Instant Messages & & $0.873 / 0.762$ \\
\hline $\begin{array}{l}\text { The approvals and decision making more quick because of instant } \\
\text { messaging }\end{array}$ & $0.866(5.16)$ & \\
\hline $\begin{array}{l}\text { The communication within the work place has increased because of instant } \\
\text { messaging }\end{array}$ & $0.879(6.77)$ & \\
\hline Computerized Maintenance Management System & & 0.913/0.677 \\
\hline $\begin{array}{l}\text { The speed of procurement, attending maintenance work has increased after } \\
\text { introducing CMMS }\end{array}$ & $0.829(25.38)$ & \\
\hline $\begin{array}{l}\text { There is a user friendly interface in CMMS therefore I am satisfied work } \\
\text { with CMMS }\end{array}$ & $0.874(27.98)$ & \\
\hline $\begin{array}{l}\text { Functioning and accessibility of the system is always in good condition as } \\
\text { I expect }\end{array}$ & $0.814(17.33)$ & \\
\hline $\begin{array}{l}\text { CMMS facilitates improved communication between my maintenance } \\
\text { team }\end{array}$ & $0.782(22.07)$ & \\
\hline $\begin{array}{l}\text { The present CMMS system easier since data and information are easily } \\
\text { saved and can be accessed again when needed }\end{array}$ & $0.810(17.76)$ & \\
\hline Job Satisfaction & & $0.912 / 0.512$ \\
\hline $\begin{array}{l}\text { My workplace is well-equipped with up-to-date equipment such as } \\
\text { physical facilities available for CMC (email, viber, what's up, web base } \\
\text { applications, etc) }\end{array}$ & $0.703(8.71)$ & \\
\hline $\begin{array}{l}\text { There is no tension at my workplace, because CMC systems increased } \\
\text { organizational commitment and reduced work stress }\end{array}$ & $0.824(25.69)$ & \\
\hline $\begin{array}{l}\text { The availability of CMC helps to develop relationships, so there is } \\
\text { improvement in teamwork at my workplace with CMC }\end{array}$ & $0.693(11.68)$ & \\
\hline $\begin{array}{l}\text { I can deliver maximum output in par with my ability using CMC in my } \\
\text { present work }\end{array}$ & $0.741(14.44)$ & \\
\hline $\begin{array}{l}\text { The company policy on CMC system matches with my interests and } \\
\text { expectations }\end{array}$ & $0.756(15.89)$ & \\
\hline I recommend CMC system for other government and private organizations & $0.6(7.29)$ & \\
\hline $\begin{array}{l}\text { I am pleased to work with CMC it has less paper work and can store files } \\
\text { electronically }\end{array}$ & $0.632(6.59)$ & \\
\hline $\begin{array}{l}\text { Since I am provided an adequate training on the CMC systems I am happy } \\
\text { to work with CMC }\end{array}$ & $0.688(10.67)$ & \\
\hline $\begin{array}{l}\text { I am happy to work with CMC because it delivers the service what I } \\
\text { expected }\end{array}$ & $0.797(17.58)$ & \\
\hline $\begin{array}{l}\text { I feel more committed to the organization because CMC System allows us } \\
\text { to be better informed and increases information sharing }\end{array}$ & 0.707 (11.67) & \\
\hline
\end{tabular}




\section{DISCUSSION}

The main aim of this research is to examine how computer mediated communication (CMC) systems such as e-mails, IMs, CMMS impact on job satisfaction of employees in Ceylon electricity Board. The results of the study confirmed a positive and significant impact of electronic mails on job satisfaction of employees. This finding is in line with the findings of Bob \& Sooknanan, (2014); and Urquhart, Bommelje, \& Schmid, (2002). Moreover, based on the findings of Bob \& Sooknanan, (2014), it is evident that the majority of employees felt that email usage had increased productivity and efficiency in the workplace. Based on Mukahi, Nakamura, \& Not, (2003) email usage is highly important for employees as well as for the performance of organization. Further he says that those organizations managing $\mathrm{CMC}$ well can gain $\mathrm{CMC}$ effects such as increase employee job satisfaction. In addition, the result of the study reveals that positive and significant impact is found between instant messaging (IM) and job satisfaction. Many of the studies (Chang \& Wan-Zheng, 2014) suggest that IM impact to the employees' job satisfaction. Further, they suggest that the management team of an organization should try to construct a new organizational culture of using IM for communication and problem solving. Also as a support for these findings, Mahatanankoon, (2010) expresses that instant messaging leads to creativity and influence to increase the job satisfaction. As claims of Iskandar, Arham, \& Shohaime, (2017) there is significant relationship between the uses of instant messaging with performance. Instant messaging is one of the more prominent computer mediated communications which is able to boost an instant reaction, similar to face to face communication. Ou, Sia, \& Hui, (2013) and Cameron \& Webster, (2005) described instant messaging allows employees to communicate in real time and shows those who are online and currently available to receive messages.

According to the findings of the research two dimensions of electronic mails and CMMS have positive significant impact on job satisfaction. Since CMMS is implemented only in the Transmission division of CEB, this finding will help higher management to step forward for CMMS implementation in other divisions of the CEB also. As well as this results shows that investing on CMMS implementation in the organization is worth. Therefore, managers can pay more attention on developing facilities for electronic mailing and CMMS without any hesitation. Rastegari \& Mobin, (2016) says that electronic communication between offices in an organization improve with CMMS because they can send work assignments to maintenance workforce through mobile devices and so they can operate more efficiently in the field, for timely completion of required maintenance and repairs. So this finding help mangers to decide whether they can extend their communications tools of CMMS to increase the job satisfaction more. 


\subsection{Managerial Implications}

Quaresma, da Silva, \& Marreiros, (2013) empirically studied the use of e-mail in an organizational context, using a sample of the Portuguese population with an active e-mail account assigned by the employer. The results show that most users have what is considered appropriate behavior and show the positive significant impact on job satisfaction. Therefore, in consist with previous studies this study also positively related for empirical study. Therefore, according to these findings the mangers should consider solutions for enabling a better management of e-mail by its employees by paying more attention on email security. The responding speed, easiness of expressing ideas and work easiness in electronic mails are more important in achieving higher level of job satisfaction. As well as the managers can understand by this finding there the user friendly interface, good access condition, save and re access data and making good communication among team in CMMS are more important in achieving higher level of job satisfaction.

On the other hand, the results show that there is a positive and a significant impact of instant messaging on job satisfaction. Therefore, managers should have to pay their more and more attention in order to improve instant messaging as one of the communication media in an organization. Some IM applications can use push technology to provide real-time text, which transmits messages character by character, as they are composed. More advanced instant messaging can add file transfer, clickable hyperlinks, Voice over IP, or video chat (Lee, 2011). Therefore, such findings imply managerial efforts should be paid to facilitate the good IM application than present to improve the employee's job satisfaction. Cho, Trier, \& Kim, (2005) identified that IM as a double-edged sword. That means IM usage has both positive and negative impacts on employee's job satisfaction and performance. Therefore, managers have huge responsibility to identify this negative impacts and get decisions to eliminate them. However, Cho, Trier, \& Kim, (2005) further states that IM can usefully increase other $\mathrm{CMC}$ tools and create an effective and comprehensive $\mathrm{CMC}$ environment in the workplace therefore it leads to better work performance of employees. So academics can do further study to find the way to use IM more effectively and comprehensively in the workplace in future.

On the other hand, the study conducted by Iskandar, Arham, \& Shohaime, (2017) one of the public service departments in Malaysia with 132 respondents found that there is significant relationship between the use of instant messaging and social network with performance. Instant messaging is one of the more prominent computer mediated communications which is able to boost an instant reaction, similar to face to face communication. Ou, Sia, \& Hui, (2013) and Cameron \& Webster, (2005) described instant messaging allows employees to communicate in real time and shows those who are online and currently available to receive messages. Therefore, there should be a proper mechanism to increase instant messaging usage in an effective way in public sector in Sri Lanka somewhat advance than present. 


\subsection{Limitations and Future Research}

Executive grade engineers and medium level technical service grade employees at transmission division were the key respondents in this study. However, the other employee categories and other divisions of the CEB could have different response for the study. The sample size was limited to 100 respondents and this too could hinder the generalization of the findings. In this research considered only three CMC dimensions which influence the job satisfaction. But there are more CMC dimensions used as organizational communication present. In this study I selected reputed leading company in public sector. But the employees in another public sector organization or private sector organization could have respond differently. Therefore, it is important to consider more CMC dimensions in private sector organizations as well in future studies. In this study, only examined the positive effects of CMC in the workplace. Future research on comparing the advantages and disadvantages of using these CMC and addressing their impacts on individual performance can enhance the entire study. The research was limited to the internal organizational communication of CMC. In future studies it can be consider external organizational communication in $\mathrm{CMC}$ with the customer satisfaction or it can be study how CMC system impact on the revenue collection of the organization. 


\section{REFERENCES}

Anton, C., (2012) McLuhan, Formal cause, and the Future of Technological Mediation. Review of Communication, 12(04), pp. 276-289.doi: 10.1080/15358593.2012.687115

Attar, G. A., \& Sweis, R. J. (2010) The Relationship between Information Technology Adoption and Job Satisfaction in Contracting Companies in Jordan. Journal of Information Technology in Construction (ITcon), 15, pp.44-63. http://www.itcon.org/2010/3.

Bagozzi, R. P., Yi, Y., \& Phillips, L. W. (1991) Assessing Construct Validity in Organizational Research. Administrative Science Quarterly. pp. 421-458.

Balouch, R., \& Hassan, F. (2014) Determinants of Job Satisfaction and its Impact on Employee Performance and Turnover Intentions. International Journal of Learning \& Development. pp. 120-140.

Bälter, O. (1998) Electronic Mail in a Working Context. Nada, Royal Institute of Technology, Sweden: Interaction and Presentation Laboratory (IPLab).

Beal, V. (2019) Email - electronic mail. Webopedia.

Belle, J. P., Hall, N., Riekert, E., \& Muganda, N. (2007) Exploring the Impact of Computer-mediated Communication on Interpersonal Relationships: A Tentative Model Using Characteristics and Behavioural Outcomes. Alternation, 14 (1).

Bob, K. \& Sooknanan, P. (2014) The Impact of Computer Mediated. Advances in Journalism and Communication, 02, pp. $45-50$

Bordi, L., Heikkilä, K., \& Okkonen, J. (2014). Digital Work Environment And Employees' Satisfaction With Customer Work.

Brief, A. P., \& Weiss, H. M. (2002). Organizational Behavior: Affect in the Workplace. ResearchGate, 53, 279307.

Cameron, A. F. \& Webster, J., (2005). Unintended consequences of emerging communication technologies: Instant Messaging in the workplace. Computers in Human Behavior, 21(1), pp. 85-103.

Carmines, E. G., \& Zeller, R. A. (1979). Reliability and Validity Assessment (Vol. 17). Thousand Oaks, CA: Sage.

Chang, H.-J., \& Wan-Zheng, I. (2014). Instant Messaging Usage and Interruptions in the Workplace. International Journal of Knowledge Content Development \& Technology, 4(2), 25-47

Chauhan, S. P. \& Singh, D. . S., (2016). Study Of Computerized Maintenance Management System (Cmms) And Computer Aided Maintenance Planning (Camp) In Production System. International Journal Of Scientific \& Engineering Research, 7(12), Pp. 315-318.

Cho, H.-K., Trier, M. and Kim, E. (2005). The use of instant messaging in working relationship development: A case study, Journal of Computer-Mediated Communication, $10, \quad 4$ : http://jcmc.indiana.edu/vol10/issue4/cho.html

Cohen, S. (1988). Psychosocial Models of the Role of Social Support in the Etiology of Physical Disease. Health Psychology, 7, $269-297$.

Daft, R. L., \& Lengel, R. H. (1986). Organizational Information Requirement, Media Richness and Structural Determinants. Management Science, 32, 554-571. 
Dahanayake, C. (2015). Discursive-Linguistic Practices and the Construction of Identity in the Sri Lankan SMS, Social Affairs: A Journal for the Social Sciences, 1(2), 15-32.

Day, A., Scott, N. \& Kelloway, K., (2010). Information and Communication Technology Implications for Job Stress and Employee Well-being. Research in Occupational Stress and Well Being, 8, pp. 317-350.

Deal, J. J. (2007). Retiring the generation GAP. San Francisco: Jossey-Bass/Wiley.

December, J. (1997). Notes on defining of computer-mediated communication. Retrieved February 25, 2012, from http://www.december.com/cmc/mag/1997/jan/december.html

DeSanctis, G. And Poole M.S. (1994). Capturing the Complexity in Advanced Technology Use: Adaptive Structuration Theory. Organization Science, 5(2), 121-147.

Dhir, S. (2018). The Changing Nature of Work, Leadership and Organizational Culture in Future Ready Organizations. Claremont: Claremont McKenna College.

Epure, D. T., Ionescu, A., \& Nancu, D.. (2013). The Impact of Communication in Job Satisfaction: an Empirical Investigation within Romanian Companies. Galati: Fascicle I. Economics and Applied Informatics.

Fish, F.E. (1990) Wing Design and Scaling of Flying Fish With Regard to Flight Performance. Journal of Zoology, 221 (3), pp. 391403.

Fornell, C., and Larcker, D. F. (1981). Evaluating Structural Equation Models with Unobservable Variables and Measurement Error. Journal of Marketing Research, (18:1), pp. 39-50.

Forza, C. (2002) Survey Research in Operations Management: A Process-Based Perspective. International Journal of Operations \& Production Management, 22 (2), pp. 152-194.

Fulk, J., Schmitz, J., \& Steinfield, C. W. (1990). A Social Influence Model of Technology Use. In J. Fulk \& C. Steinfield (Eds.), Organizations and Communication Technology, pp. 117-140. Newbury Park, CA: Sage.

Giri, V. N., \& Kumar, P. (2010). Assessing the Impact of Organizational Communication on Job Satisfaction and Job Performance. National Academy of Psychology (NAOP) India.

Gopal A, Bostrom, R.P. \& Chin, W.M. (1993) Applying Adaptive Structuration Theory to Investigate the Process of Group Support System Use. Journal of Management Information Systems 9(3), 45-69.

Gush, J. (1999). The Use of Computer Mediated Communication in the Industrial Placement Year. Emeraldinsight, 41 (2), 63-72.

Hair, J. F., Black, W. C., Babin, B. J. \& Anderson, R. E., (2007). Multivariate Data Analysis. Seventh ed. s.l.:Alaeddine Bagga.

Herzberg, F. (1968). One More Time: How Do You Motivate Employees?. Harvard Business Review. 46 (1): 53-62.

Higgins, L.R., Brautigam, D.P. and Mobley, R.K. (1995), Maintenance Engineering Handbook. 5th ed., McGrawHill Inc., New York, NY

Iskandar, A. I., Arham, A. F., \& Shohaime, N. (2017). The Use of Social Media, E-Mail and Instant Messaging as the Predictors of an Employee's Work Performance. Journal of Academia UiTM Negeri Sembilan , 5, 127136.

Jacobs, M. A., Yuo, W., \& Chavez, R. (January 2016). The Effect of Internal Communication and Employee Satisfaction on Supply Chain Integration. ScienceGate, 171(1), 60-70. 
Jayalal, S., \& Balasuriya, U. C. (2015). Impact of Social Network Usage on the Job Performance of IT Professionals in Sri Lanka. Kelaniya: ResearchGate.

Kim, J. (2002). Interpersonal Interaction in Computer Mediated Communication (CMC) : Exploratory Qualitative Research based on Critical Review of the Existing Theories, Proceedings from the Annual Meeting of the International Communication Association, San Diego, California, pp. 1-26.

Koschmann, M. A., (2012). Developing a Communicative Theory of the Nonprofit. Management Communication Quarterly, 26(1), pp. 139-146.

Kumar , P. M. (2002). Job satisfaction among permanent and contractual information technology workers. Temple University: Unpublished manuscript.

Larson, G. W. (2011). Instant Messaging. Ensiclopedia Britannica.

Lau, K. (2014). Computer-Mediated Communication: Fresno: California State University.

Lee, J., Park, D. and Han, I. (2011), The Different Effects of Online Consumer Reviews on Consumers' Purchase Intentions Depending on Trust in Online Shopping Malls: An Advertising Perspective. Internet Research, 21 (2), pp. 187-206. https://doi.org/10.1108/10662241111123766

Locke, E. A. (1976). The nature and Causes of Job Satisfaction. Handbook of Industrial and Organisational Psychology.

Mahatanankoon, P. (2010). Exploring the Impact of Instant Messaging on Job Satisfaction and Creativity. International Conference on Information Resources (pp. 1-10). CONF-IRM 2010 Proceedings.

Mertena, F. \& Gloorb,. P., (2009). Too Much E-Mail Decreases Job Satisfaction. Georgia, USA., Science Direct. Maslow, AH (1954), Motivation and Personality, Harper, New York.

Mertena, F. \& Gloorb, . P., (2009). Too Much E-Mail Decreases Job Satisfaction. Georgia, USA., ScienceDirect.

Metz, J. M., (1992). Computer Mediated Communication:Perception of a New Context, Chicago II: Paper presented at the speech Communication Association.

Mukahi, T., Nakamura , M., \& Not, R. D. (2003). An Empirical Study on Impacts of Computer-Mediated Communication Management on Job Satisfaction. Adelaide, South Australia: 7th Pacific Asia Conference on Information Systems,.

Murasugi, K \& Miki, S (1990), Double dual systems of work motivation: an empirical research on the MultiMotivation Theory in work organization (part 1). Journal of Japan Industrial Management Association, 41 (3), pp. 178-184.

Okwudili, O. M. (2012). Determinant of Effective Job Satisfaction in Public Sector Organization. University Of Nigeria: Department Of Management Faculty Of Business Administration.

Ou, C. X., Sia, C. L., \& Hui, C. K. (2013). Computer-mediated Communication and Social Networking Tools at Work. Emeraldinsight.

Palme , J. (2000). A Personal History of CMC. Honorary Publication.

Paraskeva, W., Eriksson, Y., Johansson, G. \& Peter, A. (2019) Visual Representations for Communication in Geographically Distributed New Product Development Projects. Journal of Engineering Design, 30, pp. 89, 385-403, DOI: 10.1080/09544828.2019.1661362 
Quaresma , R. F., da Silva , S. P., \& Marreiros , C. G. (2013). E-Mail Usage Practices In An Organizational Context: A Study With Portuguese Workers. Journal of Information Systems and Technology Management, 10 (1), pp. 05-20.

Rastegari, A., \& Mobin, M. (2016). Maintenance Decision Making, Supported By Computerized Maintenance Management System. Tucson, AZ, USA: The 2016 Reliability and Maintainability Symposium (RAMS®).

Rouse, M. (2008). Unified Technology Communications Basis. Tech Target.

Rowley, J. (1999). Computer Mediated Communication - is it Good for Organizations. Ormskirk: Industrial and Commercial Training.

Saleem, S., Majeed, S., Aziz, T., \& Usman, M. (February 2013). Determinants of Job Satisfaction among Employees of Banking Industry at Bahawalpur. Journal of Emerging Issues in Economics, Finance and Banking (JEIEFB), 1(2), 150-162.

Samarawickrama, P. (2017). Factors that motivate to use Computer mediated Communication (CMC) on Faculty Reaserch Productivity in SRi Lankan. Nugegoda: Knowledge Organization in Academic Libraries.

Sayago, S., Sloan, D., \& Blat, J. (2011, September). Everyday Use of Computer-Mediated Communication Tools and its Evolution Over Time: An Ethnographical Study with Older People. Interacting with Computers, pp. 543-554.

Sias, P., Pedersen, H., Gallagher, E., Kopaneva, I. (2012). Workplace Friendship in the Electronically connected Organization. Human Communication Research, 38, 253-279.

Simpson, J. (2002). Computer Mediated Commuication. ETL Journal.

Smith , W. P., \& Tabak, F. (2009). Monitoring Employee E-mails: Is There Any Roomfor Privacy? ResearchGate.

Stasser, G, (1992). Pooling of Unshared Information during Group Discussion. InS. Worchell, W. Wood, \& J.A. Simpson (eds.), Group processes and productivity(pp.48-67). Newbury Park, CA: Sage

Stefan, H. (2008) Asynchronous \& Synchronous E-Learning. Educause Quarterly, 3, 51 - 55.

Tu, C. H. (2002). The Impacts of Text-based CMC on Online Social Presence. The Journal of Interactive Online Learning, 1, 1-24.vog

Urquhart, S., Bommelje, R., \& Schmid, W. (Spring 2002). The Impact of Computer-Mediated Communication on the Workplace. The Florida Communication Journal, 30, 12-24.

Waldeck, J. H., Seibold, D. R., \& Flanagin, A. J. (2004). Organizational assimilation and communication technology use. Communication Monographs, 71(2), 161-183.

Weiss, H. M. (2002). Deconstructing JobSatisfaction (12 ed.). Human Resource Manangement Review.

Wellman,B., Salaff, J., Dimitrova, D. \& Garton,L (1996) Computer Networks as Socila Networks: Collaborative work, Telework, and Virtual Community. Annual Review of Sociology, 22, 213 - 238.

Yu, B. (2011). Computer mediated Communication system. Beijing: Triple C. 